\title{
Promoting the Rejuvenation of the Wuhan-style Culture with the Training and Education of Equestrian Talents
}

\author{
Gang $\mathrm{YU}^{1}$ and Wei-ping $X \mathrm{XIONG}^{2, *}$ \\ ${ }^{1}$ Wuhan Business University, Wuhan, Hubei, 430056, China \\ ${ }^{2}$ Institute of Physical Education of Baoshan University, Baoshan, Yunnan, 678000, China \\ *Corresponding author
}

Keywords: Equestrian, Personnel training, Wuhan-style culture.

\begin{abstract}
This paper from the connotation of the Wuhan-style culture, analyze training of equestrian talents can provide talent support to Invigorate the Wuhan-style culture, and can Forming characteristics by itself, Become the new bright spot which in Creating Wuhan-style culture, Discuss the significance of training of equestrian talents to Invigorate the Wuhan-style culture.
\end{abstract}

\section{The Connotation of the Culture of the Wuhan-style}

Culture is a complex phenomenon. It seems that any phenomenon can be attributed to literature.Therefore, it is difficult to simply define it. At present, the more common view is that Culture is the continuous transformation of nature and the continuous transformation of society. What is created is not only the total sum of material wealth, but also spiritual wealth. It is the product of human civilization. As a component of cultural phenomenon, every city they also have their own unique culture, such as Beijing's "Beijing Culture" and Shanghai's "Shanghai style" culture. Guangzhou has "south of the Five Ridges culture" and so on. As the central city of central China, Wuhan has gradually formed a unique city culture centered on Wuhan in the long period of development, because of its economic and cultural influence and radiation on the surrounding areas-- Wuhan-style culture. The culture of the Wuhan-style embodies the spirit and human environment of a city, which affects all aspects of architecture, language, literature and art, clothing and so on, such as the "Wuhan-style Costume", which has been famous all over the country.

\section{The Dilemma and Way out of the Wuhan-style Culture}

As a part of Jingchu culture, the Wuhan-style culture has a long history of 3500 years and accumulated rich cultural details. Wuhan is a famous historical and cultural city with a long history of civilization. It is also the capital of Hubei provincial capital and the political, economic and cultural center, the middle reaches of the Yangtze River and the hub of traffic in the north and south. Wuhan is the city of Panlong, the hometown of Yellow Crane and the holy land of the first righteousness. There are great words of Dayu, Qu, Qin, Li Bai, and the cultural treasures of Chu opera, Han Opera, shadow play, and Han Embroidery. But perhaps the cultural resources are too rich, but it is difficult to highlight the focus, causing us not to represent the Wuhan culture of the city card, not to build the city of Wuhan cultural brand, resulting in the cultural characteristics of the Han faction is not distinct, the spread is not widespread and other difficulties. In China's famous big cities, Beijing has "Beijing school culture", Shanghai has "Shanghai culture", and Guangzhou has "south of the Five Ridges culture".and others include Dalian's "football culture", Qingdao's "beer culture" and Weifang's "kite culture". These distinctive features of the city culture have made people impress the corresponding cities, and the attractiveness and competitiveness of these cities have been added into the city, and the development of the corresponding cities has been promoted. What kind of characteristic culture will Wuhan-style culture show? This is what Wuhan has been exploring, but so far no satisfactory answer has been found. For a long time, Wuhan will build Chu culture as the basis for the construction of Wuhan-style culture, but the effect is not satisfactory. This is because Chu culture compared with other types of regional culture, due to its independent 
development period more than 2000 years ago, there was a partition in the middle. The lack of other regional cultures, such as the good continuity of South of the Five Ridges culture, has greatly weakened the brand appeal of Chu culture. Therefore, Wuhan must explore other attractive characteristic culture, and strive to build a brand of urban culture as a basis for the construction of Wuhan-style culture. As a part of Wuhan culture, equestrian culture, represented by equestrian sports, has its distinctive characteristics and tremendous influence. Therefore, we should vigorously develop horse racing and promote the revitalization of Wuhan-style culture" by training equestrian talents.

First of all, horse racing is a noble and popular worldwide sport.Most countries and regions are flourishing and are widely loved by people. 40 years after the equestrian movement in the ancient Greek Olympic Games, the horse racing was separated from the equestrian sport. The horse racing did not take the carriage to the race, Instead of riding the horse directly by the rider, to pick up the horses with excellent genes to breed. In the history of human horse racing, each horse racing activities both inheritance and innovation, horse racing in various countries although not the same, but the development is not balanced, all countries are interrelated between the exchanges and mutual learning, so that modern horse racing entered a diversified fair to stimulate the interesting game. Modern racing originated in Britain, thoroughbred, which is now active in the world is breeding out of three stallion in the Arabia peninsula. In ancient China, there was a long history of horse racing. The story is well known that Tian Ji's use of tactics which with the lower horse to the upper horse, a middle horse to a lower horse, upper equine horse to middle horse, Winning the horse of the prince of Qi and winning a huge bonus. It shows that the horse racing was held early in the ancient China. Modern horse racing, no matter what kind of competition is determined by the time of the game, so the main reason to decide the good and bad of the game is the horse, the horse's speed, endurance and blood on the performance of the play a decisive role.

At the same time, the game the horse movement has also created a lot of employment opportunities and economic values for the society. One of the economic pillars of many countries and regions plays a vital role in social and economic development.An important role to promote. For example, in Australia, the horse racing industry is its fourth largest industry.Next to wool, mining and education, it provides more than 200000 per year. GDP of 6 billion 300 million of industry opportunity and contribution.

Secondly, Wuhan itself has a long history of horse racing, a good base for horse racing and a strong cultural background for horse racing. In the early twentieth Century, Wuhan was the three largest Racecourse in the west, China and the world.

Therefore, Wuhan once enjoyed the reputation of "horse racing capital". After the reform and opening up, Wuhan was also one of the first cities to apply for commercial horse racing to the relevant departments of the state. Moreover, Wuhan was built in 2003, the largest and most advanced Eastern horse city horse racing center in the country so far, with the material basis for carrying out the horse racing. Since 2003, the International Horse Racing Festival has been held in Wuhan every year. The "Wuhan International Horse Racing Festival" has been held for 15 consecutive years. Jockey Festival invites national and world top horse racing athletes to participate in the competition, in order to promote and promote the development of horse racing in Wuhan. By holding the horse racing festival, people can learn about horse racing and horse racing, and eventually love horse racing. In addition to the horse racing festival, Wuhan also vigorously promoted the popularity of the horse racing movement, not only enriching the people's sports and cultural life, and satisfying the people's love for equestrian and speed racing, but also has a far-reaching impact on the promotion of horse racing, the spread of $\mathrm{Ma}$ Wenhua, and the revitalization of Chinese horse industry. It is important that Wuhan city promote the protection and excavation of urban cultural heritage through the vigorous development of the horse racing, and make the horse culture into the category of Wuhan city culture, and establish the status of Wuhan as the "horse race" of China, and build the foundation of the "Wuhan-style culture".

Third, as the central city of central China, Wuhan has developed very rapidly in recent years. Great achievements have been made in all fields, especially the economic strength of the city has 
been greatly enhanced. GDP has crossed hundreds of billions of steps in a continuous 5 years, from the big 2002 About 149 billion 300 million yuan quickly jumped to a breakthrough of 10000 billion yuan in 2016, and the improvement of urban economic strength, people's living standards have been greatly improved, and the demand for cultural life, including sports and entertainment consumption, will also be greatly improved, especially for new, fashionable and high-end sports sports such as horse racing. It will also increase substantially, which will surely promote the vigorous development of horse racing in Wuhan.

At the same time, Wuhan is building a tourist city. The issuance of horse lottery will directly promote tourism in Wuhan, thus stimulating tourism consumption in Wuhan. The Wuhan speed racing championship and Wuhan International Horse Racing Festival has been held for 15 years, and it has now become another city card in Wuhan. Especially since November 2010, with the year of Wuhan, the event of horse racing began to normalize, Launch the Horse Racing Tour every Saturday (except for special circumstances), The Wuhan horse racing has received unprecedented attention from both domestic and foreign counterparts. The rotation of the media, many tourists come to watch the games on high-speed rail. All of this significantly increased the impact of Wuhan as a landlocked city, When people mention Wuhan is no longer the "Yangtze River bridge" and "Yellow Crane Tower" will be "the horse racing" and" Wuhan Eastern equestrian City ". Horse racing will promote Wuhan's tourism upgrade, at the same time, it will promote the development of the third industry in Wuhan, and accelerate the industrial transformation in Wuhan.

The domestic horse industry is very backward compared to the foreign horse industry developed countries, but because of the backwardness, the prospect of the horse industry in our country will be very broad. It will play a great role in the economic growth of our country. The future horse industry will become a new rising sun industry in our country. As the "capital of horse racing" in China, Wuhan should actively promote the pilot work of horse racing in Wuhan. At the same time, the layout of the other subsidiary industries of the horse industry will be accelerated, seize the opportunity to occupy market share. Thus making the horse industry a "barometer" of Wuhan's economy.The rapid and healthy development of horse racing is inseparable from the support of horse racing talents. Therefore, the cultivation of equestrian talents is a pressing matter of the moment.

\section{The Promotion of Equestrian Talent Training to the Revival of Wuhan-style Culture \\ Providing Talent Support for the Rejuvenation of the Culture of the Wuhan-style}

In the era of knowledge economy, higher education is faced with the problems of old professional transformation and new specialty establishment. Especially after urban cultural construction has become a new economic growth point, the professional innovation of higher education is directly related to the prosperity of urban cultural construction. To promote the revitalization of the Han culture through horse racing is inseparable from the support of a large number of horse racing talents. Without a large number of horse racing talents, there can be no real horse racing. Because of the short time to carry out the horse racing in China, there are not many people who know the sport, and the quality of the staff in the horse racing is generally not high, and the horse racing practitioners who have received regular professional education are rare. The lack of horse racing talents has seriously hindered the healthy development of horse racing and has become the bottleneck of Wuhan's "horse race capital". Take the employees of Wuhan Dongfang City as an example: after the enterprise research, the demand for the competition organization and management posts in 2016 is about 130 people, more than 1200 people will be reached in the next three years, the demand for jockey posts will reach 56, the demand for the horse house management and the horse nursing posts will reach more than 300, and the demand for the post will reach 657 people. Therefore, the training of talents in horse racing industry has become a top priority, providing talent support for the revival of Wuhan-style culture.

In order to alleviate the plight of the lack of talent in Wuhan horse racing, the Wuhan Business University pioneered the "horse racing industry management" in the country, and established the 
first national equestrian college in cooperation with Wuhan Oriental Shenma Group and its subordinate agencies, Wuhan orient horse city.

Wuhan Business University was the predecessor of the Wuhan Commercial Service College in the 60s of last century. In the course of running a school for nearly 60 years, Gradually formed to based on Wuhan, Facing Hubei, Facing the grass-roots level, Facing the modern service industry Highlight the characteristics of business education.close to the market development and talent needs to set up the country's first equestrian college, develop equestrian talents, and the enterprises selected by the school specialized personnel in the personnel training and teaching management, and distinguished China MAXIE and well-known horse industry experts as a visiting professor. To construct the training mechanism of the cooperative talents of school enterprise, school and enterprise.The two sides cooperated and participated by the school and the enterprises. In order to give full play to the college education and enterprise practical skills training advantages, strengthen professional construction, Wuhan Business University and the Wuhan Jockey Club Limited signed the agreement to build equestrian college, a professional equestrian academy construction office, office, office training training (training institutions such as the office of the permanent Wuhan Oriental City), and hired a number of equestrian industry experts as a visiting professor and part-time teachers. The establishment of the equestrian college, marking the construction and development of the equestrian professional platform and new security, also marks the school relying on the enterprises to carry out "order" training mode to further deepen, the support of the government, schools, enterprises and students' employment practice combination. During the training process of equestrian major, enterprises participate in the whole process, and put forward suggestions and suggestions. The school set up a practical teaching department specialized in docking with enterprises, and jointly trained talents. The real talent need to be more explicit training objective, teaching method and teaching means more diverse, more reasonable curriculum system and curriculum teaching more close to the post, can really improve the students' practice ability in the teaching process, students develop and adapt to the requirements of social enterprises,From 2008 to 2017, ten consecutive years, our school horse racing and equestrian major students participated in the Wuhan International Horse Racing Festival's auxiliary work. The Yangtze River daily, Hunan TV, Wuhan TV and many other media carried out thematic reports many times. Moreover, according to the requirements of talent training program jointly formulated by schools and enterprises, students are assigned second semester (summer season) and fourth semester (full semester) to carry out professional practice, and sixth semester (whole semester) to internship.The teaching management and talent training of the college, such as the president of the eastern Shenma Group and the president of the sports and equestrian College of Wuhan business college, are both the president of the equestrian college, co operating with the office, the office of the practice training and so on. The professional teachers are stationed in the enterprise by the school to assist the enterprise to carry out the practice training management and be employed specially. The Chinese Ma Association and famous horse racing experts at home and abroad serve as the visiting professors, and build the training mechanism of the cooperative talents for the professional production and learning of the horse racing industry management, and provide the talent support for the rejuvenation of the Chinese culture. Once a large number of advanced applied talents of horse racing industry can be relieved, the horse racing in Wuhan can be relieved.

The Joint School of Wuhan Business University and the Wuhan Jockey Club Limited according to the cooperation mechanism of talent production enterprise, according to the requirements of knowledge, ability and quality structure of the different positions of equestrian industry by schools and enterprises, to develop the talent training scheme, the joint development of training courses, both resource sharing, joint training specialized personnel for equestrian industry development. In the process of personnel training in the enterprise, high degree of participation, teachers shared by Wuhan Business University and the Wuhan Jockey Club Limited. the young teachers of Wuhan Business University through to the Wuhan Jockey Club Limited testing exercise in the enterprise work practice learning style, the organic combination of theoretical knowledge and practice of classroom skills, improve their professional theory level and practical ability. In addition to the 
introduction and training, the external combination of strengthening faculty building efforts, in order to improve the teaching level, hired a number of domestic and foreign well-known equestrian industry experts as a visiting professor, together to create a high level of theory and practice skills compound "double teacher" team, to meet the actual needs of emerging equestrian professional training.

Through these ways, the talents of equestrian sports are trained to provide a solid guarantee for the development of the equestrian movement in Wuhan. It can alleviate the predicament of the shortage of talents in Wuhan horse racing, and the prosperity and revitalization of the Han culture must be expected soon.

\section{Forming a New Feature and Creating New Highlights of the Wuhan-style Culture}

The cultivation of equestrian talents has become a new highlight of Han culture. The training of equestrian talents in Wuhan business college embodies the development direction of modern sports industry, with distinctive features of the times, and has received unprecedented attention from both domestic and foreign counterparts. The universities of the United States, Britain, Australia, New Zealand and other countries have come to school, exchange and express their willingness to cooperate, and the Chinese Youth Daily The Chinese daily, Hongkong Wenhui, the Hubei daily, the Central People's broadcasting station, the Hunan TV station, the Taiwan TV station and other media have made special reports. It is affirmed that the Wuhan business school has taken the lead in opening the social sports (the direction of the horse racing industry management) and the creation of the equestrian college. The training of the horse racing talents is fully embodied in the industry. The characteristics of the market and the direction of professional development. All these have greatly expanded the influence of Wuhan as an inland city, and the popularity of the city has been rising, which has become a new highlight of the Wuhan-style culture.

\section{Conclusion}

As an aristocratic movement, equestrian movement is still a new sport in our country. Wuhan as a national civilized city, National Central City, megacity behemoth, has the foundation and ability to develop the equestrian movement. And Wuhan has 15years of experience in equestrian movement.Some of the rules of equestrian movement are already familiar, there has been a preliminary development of the conditions for the equestrian movement. Wuhan should seize the opportunity, dare to be the first, actively promoting the development of equestrian movement. The development of equestrian movement has a great effect on the promotion of Wuhan's city charm. The use of regional advantages to develop the equestrian movement in Wuhan has a role in promoting the economy of Wuhan and the whole country. In the near future, the equestrian movement will become another major engine of Wuhan and even the China's economy. At the same time, every city should have its unique culture. For Wuhan, the revival of Wuhan-style culture can not be separated from equestrian talent cultivation. Because the training of equestrian talents can provide talent support for the revival of Wuhan-style culture, and it can form its own characteristics and become a new highlight of creating Wuhan-style culture.

\section{Acknowledgement}

Fund Project: Wuhan Education Science "13th Five-Year" 2017 year project planning "Research on Integration of the Cultivation Mode of the Talents by "Production, Study, Research and Creation” in University Equestrian Major”.

Project number: 2017C153

\section{Reference}

[1] Wuhan statistical yearbook. 2015.

[2] YUGang. Talent training mechanism of industry university cooperation in horse racing industry 
management[J] Science and technology information, 2011(27): 126-127.

[3] YUGang, XiaYunjian, FangWu. Discussion on the difference of talent training of social sports guidance and management specialty in Colleges and Universities $[\mathrm{J}]$. <<Journal of Wuhan Commercial Service College $>>2013,10$.

[4] LiuYunfei, Wuxuesong, Industry university research cooperative education and applied talents training -- Based on the perspective of local application oriented Universities [J]. Journal of Jinling Institute of Technology: Social Sciences Edition, 2008, 22(3): 73-76 